\title{
ALFABETIZAÇÃO CIENTÍFICA: QUESTÕES PARA REFLEXÃO
}

\section{Scientific literacy: questions for reflection}

Francimar Martins Teixeira ${ }^{1}$

Resumo: O presente texto apresenta uma reflexão sobre os significados atribuídos à expressão alfabetização científica. Nele retomamos a origem histórica das expressões letramento e alfabetização, seus respectivos significados na área de linguagem e os desdobramentos desses significados para o ensino da língua portuguesa no contexto escolar. Em seguida, analisamos as implicações da apropriação do conceito de alfabetização no âmbito do ensino das ciências, e apresentamos proposta delimitando os usos do termo alfabetização científica, além de esclarecimentos sobre em que ele consiste. Argumentamos que alfabetização científica diz respeito a tudo aquilo que envolve a escrita e a leitura de texto científico, como a construção de entendimento e a análise das informações. Advogamos que a alfabetização científica está atrelada à alfabetização na própria língua, e que o ensino de ciências deve ser concebido à luz de objetivos educacionais mais amplos que o aprendizado de ciências per si (conhecimentos e procedimentos).

Palavras-chave: Alfabetização científica. Alfabetização. Ensino de ciências.

\begin{abstract}
This paper presents reflections on the meanings assigned to scientific literacy expressions. We return to the historical origins of literacy and literacy expressions, their meanings in the language and the meanings of these developments for the teaching of Portuguese language in the school context. Then we analyze the implications of the appropriation of the concept of literacy in the teaching of science and present a proposal outlining the uses of the term scientific literacy, as well as clarification of what it consists of. We argue that scientific literacy concerns everything involving the writing and reading of scientific texts, such as the construction of understanding and information analysis. The argument is presented that scientific literacy is linked to literacy in their own language and that the teaching of science must be conceived in the light of broader educational goals than just learning science (knowledge and procedures).
\end{abstract}

Keywords: Scientific literacy. Literacy. Science education.

\footnotetext{
${ }^{1}$ Universidade Federal de Pernambuco (UFPE), Centro de Educação, Departamento de Métodos e Técnicas de Ensino, Rua Acadêmico Hélio Ramos, s/n, sala 111, Cidade Universitária, CEP 52050-070, Recife, PE, Brasil. E-mail: <francimarteixeira@gmail.com>
} 


\section{Scientific literacy: alfabetização ou letramento científico?}

O presente texto apresenta uma reflexão sobre o sentido da expressão alfabetização científica. Nele retomamos a origem histórica das expressões letramento e alfabetização, seus respectivos significados na área de linguagem e os desdobramentos desses significados para o ensino da língua portuguesa no contexto escolar. Em seguida, refletimos sobre as implicações da apropriação do conceito de alfabetização no âmbito do ensino das ciências, e, sob inspiração de estudos na área de linguística, apresentamos proposta delimitando os usos do termo alfabetização científica, além de esclarecimentos sobre em que ele consiste. Tanto alfabetização científica (AULER; DELIZOICOV, 2001; CHASSOT, 2000) quanto letramento científico (MAMEDE; ZIMMERMANN, 2005; SANTOS; MORTIMER, 2001) têm sido, no Brasil, traduções para o termo inglês scientific literacy. De acordo com Sasseron e Carvalho (2008, p. 334):

Podemos perceber que no cerne das discussões levantadas pelos pesquisadores que usam um termo ou outro estão as mesmas preocupações com o ensino de ciências, ou seja, motivos que guiam o planejamento deste ensino para a construção de benefícios práticos para as pessoas, a sociedade e o meio ambiente.

Constrói-se, assim, de acordo com tal declaração e dos que a seguem (MARTINS, 2008; SANTOS, 2007; SASSERON; CARVALHO, 2008), o entendimento de que as expressões alfabetização científica e letramento científico são variações de vocábulos para se referir ao ensino das ciências dentro do processo de escolarização básica, não havendo, à luz deste entendimento, nenhuma diferença, entre eles, de sentidos ou especificidades.

Alfabetização e letramento são aspectos da língua escrita. Sem surpresa, ambos constituem, por primazia, objetos de estudo de linguistas e de educadores que têm a linguagem como foco de investigação. Estudos nestas áreas apontam que, embora os processos de alfabetizar e letrar, ainda que, por vezes, estejam inter-relacionados, são processos dissociados (MARCUSCHI, 2007; SOARES, 2004). Dito isso, demarca-se que, na área da linguagem, alfabetizar e letrar têm, cada um, suas especificidades e, diferentemente do que vem acontecendo na área do ensino das ciências, não são considerados a mesma coisa.

Reflexões sobre a pertinência do uso dos termos alfabetização e letramento para as ciências já vem ocupando a atenção de pesquisadores brasileiros da área da educação em ciências (MARTINS, 2008; PAULA; LIMA, 2007; SANTOS, 2007). Este trabalho visa ampliar a compreensão do tema, analisando os diversos sentidos atribuídos à expressão scientific literacy, além de apresentar e defender um entendimento sobre quais são os aspectos da educação a que remete o termo scientific literacy quando traduzido por alfabetização científica.

Como bem disseram Paula e Lima (2007, p. 4), "alguns termos ainda pouco compreendidos são incorporados e usados sem que as pessoas sintam a necessidade de se perguntarem o que eles significam. Viram chavões". Entendemos que pensar sobre os significados de alfabetização científica é pensar sobre as funções da educação científica, qual o seu papel, onde ela acontece e de que formas; é, em última instância, pensar sobre o que é educação científica, o que se pretende com tal educação, de que forma podemos alcançá-la e quais os modos pelos quais podemos avaliar se, de fato, os objetivos almejados foram alcançados. 
Alfabetização científica: questões para reflexão

Neste sentido, ainda que não se obtenha consenso em torno do produto desses questionamentos, ele é produtivo para oxigenar reflexões que podem vir a gerar referenciais para o planejamento da área da educação científica na realidade brasileira.

\section{Histórico dos termos alfabetização e letramento}

Segundo Soares (1998, p. 17), a palavra literacy vem do latim littera, que quer dizer letra; por sua vez, o sufixo $c y$ denota qualidade, condição. Assim, literacy é o "estado ou condição que assume aquele que aprende a ler e escrever" (SOARES, 1998, p. 17). Laugksch (2000), à semelhança de Soares, também aponta a origem latina do termo e, adicionalmente, assinala que o significado deste mudou ao longo dos séculos. No tempo de Cícero, era usado no sentido de distinguir quem aprendeu a ler dos que não aprenderam. Nesta acepção, não se considera a qualidade da leitura: aqueles que identificavam as letras estavam incluídos na categoria de leitor. Posteriormente, o termo literacy passou a ser usado em relação à competência de ler, de modo a distinguir os que tinham a competência para decodificar o que estava escrito dos que não a tinham. Os vocábulos inglês literacy e illiteracy, em francês, alphabétisme e analphabétisme, e, em português, alfabetizado e analfabeto, nomeiam, respectivamente, a distinção entre os que têm a competência para ler e os que não a têm.

Ao final dos anos de 1970 (SOARES, 2008), por sugestão da Organização das Nações Unidas (Unesco), o termo alfabetizado passou a remeter à competência do uso da leitura $\mathrm{e}$ da escrita em contextos diversos, isto é, a nomear os que, efetivamente, podiam fazer uso da leitura e da escrita para se expressarem. A UNESCO (2010, p. 297, tradução nossa) esclarece bem este sentido quando diz que é alfabetizado aquele que tem a:

[...] capacidade de identificar, compreender, interpretar, criar, comunicar, calcular e utilizar materiais impressos e escritos relacionados com contextos variados. Alfabetização envolve um contínuo de aprendizagens que capacita os indivíduos a alcançarem seus objetivos, desenvolver seus conhecimentos e potencial e participar plenamente na sua comunidade e sociedade em geral.

A partir das definições de alfabetizado e de alfabetização propostas pela Unesco, consubstancia-se outro conceito: o de analfabeto funcional. $\mathrm{Na}$ atualidade, são denominados analfabetos funcionais os indivíduos que conseguem decodificar letras, sentenças, enfim, materiais escritos, mas não conseguem fazer uso compreensivo da leitura e da escrita, isto é, apesar de lerem, não conseguem entender o conjunto do que leem ou se expressar através da escrita (MILLER, 2006; SOARES, 1998).

Estima-se que, atualmente, existem, no mundo, cerca de 800 a 900 milhões de pessoas nesta situação. Segundo relatório parlamentar do governo inglês (GREAT BRITAIN, 2009), em 2003, data do último levantamento sobre a quantidade de adultos funcionalmente analfabetos, havia, nesse país, 5,2 milhões. Dados da National Assessment of Adult Literacy (U. S. DEPARTMENT OF EDUCATION, 2004) apontam que, nos Estados Unidos, em 2003, havia 30 milhões de adultos analfabetos funcionais, o que representa $14 \%$ da população adulta 
nesta mesma condição. No Brasil, de acordo com a última Pesquisa Nacional por Amostra de Domicílios (INSTITUTO BRASILEIRO DE GEOGRAFIA E ESTATÍSTICA, 2009), um em cada cinco brasileiros - entre estes, $25 \%$ da população com mais de 15 anos - é analfabeto funcional.

Os elementos apresentados no conceito de alfabetizado, elaborado em fins dos anos de 1970 pela Unesco, anunciam, apesar de não fazê-lo com destaque, que o aprendizado do sistema de escrita deve estar a serviço dos usos da leitura e da escrita. A demarcação entre o conhecimento do código escrito e o uso deste ficou mais acentuada em 1981, quando a instituição francesa de caridade ATD Quart Monde empregou o termo illetrisme, que, em português, traduz-se como iletrado, para expressar um sentido diferente do que expressa o termo francês analphabète, em português analfabeto (UNESCO, 2010). Illetrisme foi usado para nomear os indivíduos que tinham vivenciado todas as etapas do sistema educacional da escola primária e, embora alfabetizados, não eram capazes de fazer uso efetivo da leitura e da escrita.

Em agosto de 2005, a França adotou o termo littérisme para se referir à habilidade de ler e entender um texto simples ou usar a escrita para receber ou transmitir informação. Um conceito equivalente ao que, na língua inglesa, é denominado literacy, quando este é usado para descrever a condição daqueles indivíduos que, efetivamente, podem fazer uso das habilidades de leitura e escrita. É válido destacar que, na língua inglesa, o termo literacy pode ser usado tanto em referência ao aprendizado do código escrito quanto em relação à possibilidade efetiva de uso das habilidades de leitura e escrita. Portanto, é um termo que, em princípio, ao ser traduzido para o português, pode receber o significado de alfabetização ou de letramento. Todavia, é preciso estar alerta ao se optar por um dos dois termos, pois os linguistas no Brasil, assim como ocorre na França, atribuem a alfabetização e letramento sentidos diferentes.

Credita-se a Mary Kato (1986), na obra "No mundo da escrita: uma perspectiva psicolinguística", o uso, pela primeira vez, no Brasil da palavra letramento (SOARES, 2004). A distinção conceitual entre os termos alfabetização e letramento aconteceu, no contexto nacional, dois anos depois, em 1988, apresentada por Leda Tfouni, no livro "Adultos não alfabetizados: o avesso do avesso", no qual a autora diz que, "enquanto a alfabetização ocupa-se da aquisição da escrita por um indivíduo, ou grupos de indivíduos, o letramento focaliza os aspectos sócio-históricos da aquisição de um sistema escrito por uma sociedade" (TFOUNI, 1988, p. 20).

Soares (2003), reiterando a posição de Tfouni (1988), entende que alfabetizar consiste em aprender o código escrito, e letrar, em fazer uso deste código de modo apropriado nos mais diferentes contextos sociais. Ainda na direção de idêntico entendimento, Marcuschi (2007, p. 15) é enfático ao afirmar que "não se pode confundir as diversas manifestações sociais do letramento com a escrita como tal, pois esta não passaria de uma das formas de letramento". Segundo ele, é pertinente a expressão os letramentos, no plural, de modo a demarcar a existência de diferentes práticas de letramento e níveis variados de letramento:

Deve-se ter imenso cuidado diante da tendência à escolarização do letramento, que sofre de um mal crônico ao supor que só existe um letramento. O letramento não é o equivalente à aquisição da escrita. Exis- 
Alfabetização científica: questões para reflexão

tem 'letramentos sociais' que surgem e se desenvolvem à margem da escola, não precisando por isso serem depreciados. (MARCUSCHI, 2007 , p. 15, grifo nosso)

Em outras palavras, o que Marcuschi (2007), Soares (2003) e Tfouni (1988) estão afirmando é que há uma distinção nítida entre o domínio das habilidades de ler e escrever (alfabetização) e a influência e a penetração da escrita na sociedade (letramento). Seguindo tal distinção, mesmo pessoas que não sabem ler e escrever, aquelas ditas analfabetas, que vivem em sociedades na qual a escrita é um bem social indispensável para enfrentar o dia a dia, estão sob a influência da escrita e têm apropriação dos usos da escrita. Por conseguinte, é analfabeto com algum grau de letramento, ainda que de forma mínima e dissociada do domínio do código gráfico, o indivíduo que "identifica o valor do dinheiro, identifica o ônibus que deve tomar, consegue fazer cálculos complexos, sabe distinguir as mercadorias pelas marcas, etc., mas não escreve cartas nem lê jornal" (MARCUSCHI, 2007, p. 25).

Soares (2003) nos apresenta outras ilustrações de que as práticas de letramentos não podem ser confundidas com alfabetização:

Como no filme Central do Brasil - alguns personagens conheciam a carta, mas não podiam escrevê-la por serem analfabetos. Eles ditavam a carta dentro do gênero, mesmo sem saber escrever. A personagem principal, a Dora (interpretada pela atriz Fernanda Montenegro), era um instrumento para essas pessoas letradas, mas não alfabetizadas, usarem a leitura e a escrita. No universo infantil há outro bom exemplo: a criança, sem ser alfabetizada, finge que lê um livro. Se ela vive em um ambiente literário, vai com o dedo na linha, e faz as entonações de narração da leitura, até com estilo. Ela é apropriada de funções e do uso da língua escrita. Essas são pessoas letradas sem ser alfabetizadas. (SOARES, 2003, p. 3)

Realmente, como bem disse Soares (2003), os dois primeiros minutos do filme Central do Brasil são emblemáticos em relação a exemplificar a distinção entre o ser alfabetizado e o ser letrado. Neste tempo, o filme apresenta três personagens analfabetos ditando carta à personagem Dora, que atua como escriba. A análise dessas cartas nos revela, além do entendimento da função da escrita, o pleno domínio do gênero textual carta pessoal que estes três analfabetos apresentam. Vejamos:

\section{Carta 1}

Querido,

Meu coração é seu. Não importa o que você tenha feito. Eu te amo! Eu te amo! Esses anos todos que você vai ficar trancado aí dentro. Eu também vou ficar trancada aqui fora te esperando. (CENTRAL..., 1998) 
Teixeira, F. M.

\section{Carta 2}

Seu Zé Amaro, Muito obrigado pelo que você fez comigo. Confiei em você e você me enganou. Até a chave do meu apartamento você carregou. (CENTRAL..., 1998)

\section{Carta 3 \\ Jesus, \\ Você foi a pior coisa que já me aconteceu. Só escrevo porque teu filho Josué me pediu. Eu falei pra ele que você não vale nada, mas ainda assim o menino pôs na ideia que quer te conhecer. (CENTRAL..., 1998)}

Os três personagens analfabetos do filme Central do Brasil (1998), embora ditem suas cartas a uma escriba, se assumem como produtores do texto escrito. Quem receber o texto, se não souber que eles não escrevem, certamente pensará que é do remetente a autoria do conteúdo e da escrita. A terceira mensagem é explícita em relação à autoria da produção quando a personagem diz: "Só escrevo porque o teu filho Josué pediu". Logo no início dos textos, os três se dirigem a um destinatário, respectivamente, Querido, seu Zé Amaro e Jesus, organizando suas falas de acordo com moldes da escrita e fazendo uso de fórmula linguística característica da composição textual carta pessoal.

Ao precisar o destinatário, eles se situam na posição de remetentes e delimitam a comunicação, inscrevendo-a no âmbito privado. A condição remetente-destinatário e o conteúdo das mensagens são duas outras fórmulas linguísticas características do gênero carta pessoal. De fato, os três textos, apesar de distintos em relação à informação que querem transmitir, sugerem um relacionamento próximo entre os remetentes e seus respectivos destinatários, abordando questão vinculada a aspectos do convívio entre remetente e destinatário, tal como esperado em cartas pessoais.

Diversos estudos demonstram que os gêneros textuais são artefatos linguísticos construídos socialmente para atender a objetivos determinados (MARCUSCHI, 2007; SOARES, 2003). Apesar de estarmos colocando em foco um filme com situações fictícias, estas retratam a realidade brasileira: analfabetos que recorrem a escribas para registro das suas cartas. Por isso, tomamos a situação de produção dos três textos registrados no filme como ilustrações de que indivíduos que não sabem nem ler nem escrever podem fazer uso de recursos linguísticos característicos da escrita com bastante propriedade.

No filme, percebe-se que os autores das cartas, apesar de analfabetos, dispunham de conhecimentos sobre o funcionamento textual de que faziam uso. Esse uso da escrita por quem não sabe ler ou escrever demarca que o letramento não está restrito à alfabetização. Demonstra-nos que a inserção em ambiente grafocêntrico possibilita, aos indivíduos, a apropriação das funções da escrita, ainda que estes não tenham se apropriado dos códigos de escrita. Por conseguinte, não podemos confundir letramento com alfabetização, tampouco com escolarização.

Norteados pelas evidências dos estudos da área de linguagem de que alfabetização refere-se à apropriação das habilidades de ler e escrever, enquanto letramento remete às práticas de uso da escrita, conclui-se que letramento não é equivalente a alfabetização. À luz da 
distinção entre alfabetização e letramento na área da linguagem, são pertinentes indagações que, se respondidas em investigações futuras, nos proporcionarão mais elementos para pensarmos sobre o que é educação científica. Entre essas questões, destacamos: os termos alfabetização e letramento podem ser empregados indiscriminadamente, tal como vem ocorrendo na literatura brasileira na área do ensino das ciências? O uso desses termos é apropriado para a área do ensino das ciências? Qual o sentido de ambos quando usados nesta área?

\section{Análise do termo scientific literacy}

Os termos alfabetização científica e letramento científico são empregados no Brasil para traduzir a expressão scientific literacy. Esta remonta aos anos 50 do século passado (DEBOER, 2000; HURD, 1998), quando, em junho de 1958, em relatório produzido nos Estados Unidos pela Fundação Rockefeller, sobre como o sistema educacional poderia ser usado para preparar de modo mais eficiente pessoas para viver e trabalhar em um mundo de mudanças rápidas, foi dito que: "toda pessoa educada deve ser alfabetizada/letrada em ciências" (DEBOER, 2000, p. 369). Ainda em outubro e novembro desse mesmo ano, o termo scientific literacy reapareceu em dois outros artigos: em outubro de 1958, publicado no Educational Leadership, e, em novembro de 1958, mencionado pelo presidente da Shell Chemicals Corporation.

Deboer (2000) afirma que em nenhum dos textos nada é dito explicitamente sobre o que é, de fato, uma pessoa alfabetizada/letrada em ciências. Todavia, ao assinalarem que scientific literacy seria um dos produtos do processo da educação escolar, estariam, na interpretação de Deboer (2000), diferenciando a formação de uma pessoa escolarizada da formação de uma não escolarizada. Subjacente a tal diferenciação, Deboer (2000) entende que se atribui aos escolarizados a possibilidade de esses serem mais eficientes diante de um contexto de transformações. Por conseguinte, scientific literacy envolveria a aquisição de uma herança de conhecimentos produzidos pela humanidade, que habilitaria os indivíduos a entenderem o mundo natural, tornando-os mais informados, capacitando-os a ter experiências mais "inteligentes" no cotidiano (DEBOER, 2000 p. 592).

Com base nessa perspectiva, argumentamos que a expressão scientific literacy estabelece vínculos entre ciência, leitura e escrita, colocando as três em um mesmo patamar de imprescindibilidade. Considerando que leitura e escrita são bens culturais que possibilitam a inserção nas sociedades grafocêntricas e que, também, são, nessas sociedades, habilidades cujo domínio é relevante para todos os indivíduos, interpretamos que a expressão scientific literacy transmite a ideia de que aprender ciências deveria ser algo tão imprescindível quanto aprender a leitura e a escrita, uma apropriação desejável para todos os seres humanos, a ser estabelecida como um fenômeno de massa.

Retornando aos estudos da área da linguagem, encontramos registro de que o reconhecimento da leitura e da escrita como algo a ser apropriado por todos confere a elas status elevado. No entender de Marcuschi (2007, p. 17), tal status chega a "simbolizar educação, desenvolvimento e poder". De modo dialético, a falta do domínio das duas habilidades cria um contexto de desprestígio, associado à falta de educação, de civilização e de conhecimento. Marcuschi (2007, p. 23) destaca que os planos desenvolvimentistas da Unesco assentam-se na crença de que o analfabetismo está vinculado ao atraso geral, à pobreza, à doença, enquanto 
“o progresso, a saúde e o bem-estar econômico estão igualmente de forma autoevidente vinculados com a alfabetização".

Sob o olhar dos que consideram que o analfabetismo é atraso e as habilidades de ler e escrever associam-se ao progresso e ao bem-estar econômico, é legítimo interpretar que a expressão scientific literacy denota a crença de que a ciência está no mesmo patamar de relevância da escrita e da leitura no contexto em que se busca tal progresso e bem-estar. À semelhança dessas duas primeiras habilidades, adquiri-la é condição essencial e imprescindível a todos os indivíduos. Consequentemente, deve-se assegurar em massa que todos os indivíduos se apropriem da ciência. Relembrando a análise de Deboer (2000, p. 592), scientific literacy envolve conhecimentos que tornam os indivíduos mais preparados para entender o mundo natural, possibilitando-lhes ser mais eficientes, capacitando-os a terem experiências mais "inteligentes" no cotidiano.

Entendemos que, nesta primeira instância, diferentemente do que acontece com a área de linguagem em relação aos processos de alfabetização e letramento, scientific literacy não teria sido empregado com a noção de domínio de um código, tampouco remetia às práticas de uso da ciência. Antes, sim, teria sido uma forma de destacar a relevância da popularização da ciência, de caracterizá-la como tão imprescindível quanto a leitura e a escrita, e, por decorrência, seu aprendizado deveria ocorrer em massa, atingindo todos os indivíduos.

O contexto histórico no qual emergiu o termo scientific literacy é outra evidência que nos leva a defender a nossa interpretação do sentido inicial deste termo. Quem primeiro empregou a expressão scientific literacy foram pessoas ligadas a grandes grupos econômicos nos EUA: Fundação Rockefeller e Shell Chemicals Corporation, em contexto no qual as organizações internacionais no campo da educação, impactadas pelas consequências da Segunda Guerra Mundial, orientavam, mundo afora, a formulação de políticas públicas alimentadas pelo ideal de que "o sistema educacional poderia ser usado de forma mais eficaz para preparar as pessoas para viver e trabalhar em um mundo em rápida mutação" (DEBOER, 2000, p. 586).

Para alguns, tal proposição entende educação como "fator de desenvolvimento econômico, instrumento de progresso técnico e meio de seleção e ascensão social" (SANDER, 2008, p. 161). Tal entendimento reforça nosso argumento de que scientific literacy foi, inicialmente, uma expressão empregada com a finalidade de demarcar que a ciência era imprescindível à sociedade estadunidense, um fator essencial para o progresso econômico e o bem-estar. Ainda à luz da história, verificamos que o termo apareceu, pela primeira vez, em junho de 1958, oito meses depois do lançamento (ocorrido em outubro de 1957) do satélite Sputnik pela União das Repúblicas Socialistas Soviéticas (URSS). Vivia-se, então, o período da chamada Guerra Fria, disputa não bélica entre os países capitalistas, capitaneada pelos EUA e pelo bloco de países socialistas, liderados pela URSS. O lançamento do Sputnik repercutiu nos EUA, fazendo-os sentiremse defasados nos mais diversos aspectos, sentimento esse que impulsionou o encaminhamento da reforma curricular na área do ensino das ciências e a tentativa de tornar esta área um dos pilares do ensino no âmbito escolar. Conforme Bybee (1997, p. 1):

The United States perceived itself as scientifically, technologically, militarily, and economically weak. As a result, educators, scientists, and mathematicians broadened and accelerated educational reform, the 
public understood and supported the effort, and the policy makers increased federal funding.

$\mathrm{Na}$ história, em tempos mais próximos, encontramos outra evidência a que recorremos a favor do nosso argumento de que scientific literacy foi uma expressão cunhada para assinalar que o aprendizado de ciências é tão relevante quanto a leitura e a escrita, e, por isso, deve ser assegurado a todos os indivíduos. O projeto Science for all Americans, publicado em 1989 pela Associação Americana para o Avanço da Ciência, como o título "Ciências para Todos" já anuncia, toma esta direção e emprega o termo scientific literacy, dando a ele um caráter de expressão de efeito para destacar a relevância do ensino de ciências. Vários autores propõem que o termo scientific literacy vem sendo reincidentemente utilizado para se referir ao ensino de ciências. Desta forma, em vez de se dizer ensino de ciências, fala-se em scientific literacy. Tal repetição faz deste termo um slogan (BYBEE, 1997; DEBOER, 2000; LAUGKS$\mathrm{CH}, 2000)$. Se, como slogan, falar de scientific literacy é falar do ensino de ciências, em nosso entendimento, a expressão scientific literacy é um modo de afirmar que o ensino de ciências tem a mesma imprescindibilidade da leitura e da escrita. Então, podemos acreditar que o uso deste slogan seria um modo implícito de ratificar a imprescindibilidade do ensino de ciências. Imaginamos que é esse caráter de imprescindibilidade subjacente à expressão scientific literacy o que talvez explique a opção ampla de uso do termo scientific literacy em vez de ensino de ciências.

Se, por um lado, assumir scientific literacy como um slogan aparentemente une os que usam tal expressão em torno do entendimento de que o ensino de ciências é relevante, por outro, está longe de consenso uma série de questões relacionadas a este assunto. Por exemplo, Deboer (2000), revisando pesquisas, propostas curriculares, relatórios e documentos relacionados ao ensino de ciências nos Estados Unidos, desde o surgimento do termo scientific literacy até o ano 2000, encontrou nove grupos de proposições de objetivos distintos para o ensino de ciências. Em relação às características de indivíduos scientific literated, Laugksch (2000) identificou uma diversidade ainda maior que as apontadas sobre os objetivos do ensino das ciências. Essas diversidades fundamentam as críticas de que o slogan scientific literacy é difuso, mal definido, pouco esclarecedor acerca dos aspectos que ele abarca, e de difícil mensuração (DEBOER, 2000, p. 594; LAUGKSCH, 2000, p. 90).

Somadas às críticas em relação à scientific literacy como slogan, existem, também, críticas ao termo como metáfora. Isto é, na associação da ciência (scientific) à aquisição da leitura e da escrita (literacy), tendo em vista estabelecer, de modo subtendido, uma comparação entre os dois termos, transferindo características da literacy para o scientific, e, assim, integrá-las, produzindo um termo cuja significação, para alguns, reside em atribuir à ciência a mesma relevância da escrita e da leitura. Segundo Deboer (2000, p. 594), observações cotidianas sugerem que a maioria dos cidadãos está bem em seu trabalho e em casa, apesar de não pensar como cientista, e pessoas com entendimento limitado sobre ciência funcionam bem em sociedade, muitas, inclusive, estão no topo do seu nível profissional. Por conseguinte, Deboer (2000) discorda da ideia de que scientific literacy envolve a aquisição de uma herança de conhecimentos que habilitam os indivíduos a entender o mundo natural, capacitando-os a ter experiências mais "inteligentes" no cotidiano. (DEBOER, 2000 p. 592). Utilizando as palavras de Jurgen Baumert proferidas em 1997, Deboer (2000, p. 595) diz que scientific literacy é um objetivo educacional 
relevante, mas, certamente, não é uma ferramenta cultural fundamental comparada à leitura, à escrita e à aritmética.

Para outros autores, o significado do termo scientific literacy é metafórico, e este consiste em pensar o aprendizado da ciência a partir do que já conhecemos sobre a estrutura fundamental do aprendizado da língua, tanto estabelecendo paralelos entre os domínios conceituais das áreas de linguagem e ciências quanto fazendo inferências sobre as propriedades destas áreas e a inter-relação de ambas (MARTINS, 2008). Por exemplo, alguns estudos apontam paralelos entre a condução de atividades de investigação científica e os processos de leitura e de escrita ${ }^{2}$ : em uma investigação, levantam-se questões, enquanto na redação de algo o escritor estabelece propósitos; atividades investigativas envolvem o desenvolvimento de hipóteses, enquanto na leitura há predições sobre o que se lê; em investigações desenha-se um estudo e, na leitura ou na escrita, se organizam ideias.

Alinhando-se na direção dos que pensam em scientific literacy como uma apropriação metafórica, na qual se estabelecem paralelos entre os conhecimentos já estruturados sobre o aprendizado na área de linguagem, para pensar o aprendizado em ciências, há os que têm clamado que scientific literacy é ferramenta cultural fundamental, por ser parte do processo da aquisição da leitura (HOLBROOK; RANNIKMAE, 2007, 2009; NORRIS; PHILLIPS, 2003; PEGG, 2010; YORE; PIMM; TUAN, 2007). Em outras palavras, um indivíduo plenamente alfabetizado precisa ser preparado para ter condições de fazer leitura de textos científicos. De acordo com Norris e Phillips (2003, p. 231):

Literacy in the fundamental sense is about how readers cope with text, about how they use the resources of text to determine what they mean, or might mean. Scientific literacy must comprise the interpretive strategies needed to cope with science text.

É importante esclarecer que, nesta perspectiva, ao se falar de preparo para condições de leitura de textos científicos, não se toma como foco a capacidade de decodificar o que está escrito. Antes, sim, refere-se à competência de interpretar o conteúdo da informação, que, no caso de textos científicos, além da decodificação do que é dito, envolve a identificação de evidências empíricas ou de teorias que fundamentam o que é dito, bem como interpretação de aspectos não verbais da linguagem, tais como: gráficos, tabelas, diagramas, expressões matemáticas, reflexão e capacidade de distinguir entre o que é descrição de fatos (observações) e o que é interpretação de fatos. Deste modo, sob este entendimento metafórico do termo scientific literacy, apesar de, a rigor, não existir, na ciência, um código específico a ser aprendido, tal como ocorre no processo de alfabetização na língua (LIMA; CASTRO, 2007), defendemos que é apropriado traduzi-lo por alfabetização científica.

Curiosamente, diferentemente do que tradicionalmente se destaca como expectativa para o ensino das ciências, à luz deste entendimento, o foco da alfabetização científica não é o

${ }^{2}$ Ver revisão em Liu e Akerson (2002). 
conhecimento científico (teorias, conceitos, procedimentos). Norris e Phillips (2003) dizem que a escrita e a leitura, nas situações escolares, particularmente a leitura, constituem o sentido fundamental da alfabetização científica. A respeito da leitura de textos científicos, assinalam que esta consiste na capacidade de interpretar, avaliar, inferir significados a partir do registro escrito, a partir do que o texto diz. Essas capacidades, necessariamente, não asseguram ao leitor condições de posicionar-se sobre a veracidade ou não da informação. Entretanto, tais capacidades significam o exercício do pensar, o desenvolvimento da autonomia intelectual.

Em relação ao conhecimento científico, este seria, no entender de Norris e Phillips (2003, p. 231), o sentido derivado da educação em ciências:

Scientific knowledge has an essential dependence upon texts. Although individuals portray and learn much science within oracy, such access to scientific knowledge is parasitic upon access gained through text. This is so, because, without literacy, the knowledge would not have existed, been preserved, and inherited in the first place. Hence, a concept of scientific literacy must include an essential role of text in science.

É valido destacar que, no contexto de ensino das ciências, atribuir ao conhecimento científico um sentido derivado, um papel coadjuvante, não o faz irrelevante. O que se assinala é que este conhecimento não pode per si constituir o norte (objetivo central) do ensino, mas um meio para atingir a formação de pessoas críticas capazes de analisar e relacionar informações, buscar alternativas para o que têm à frente. É um prospecto de ensino que conflita com abordagens que clamam pela necessidade de investir em ensino de ciências visando à orientação profissional, bem como a aspectos econômicos ou utilitários (conhecimento científico com fins instrumentais, aplicação prática). O conceito de alfabetização científica aqui defendido tem muitos pontos em comum com a abordagem CTS - ciência, tecnologia e sociedade. (SANTOS, 2007). Em ambas, se insere o ensino de ciências no âmbito das necessidades educacionais da maioria da população do país, buscando-se contribuições que o ensino, nesta área, pode trazer para a melhoria da qualidade de vida, a promoção da saúde e o bem-estar da população. Porém, há, na abordagem CTS, o uso do termo alfabetização científica no sentido de slogan, isto é, um produto do ensino das ciências, não se encontrando, na abordagem a CTS, a defesa enfática de formação de leitor, tal como é aqui defendido.

Em síntese, propomos que, ao se traduzir o termo scientific literacy por alfabetização científica, tenha-se em mente que esta é um aspecto peculiar do processo da alfabetização, isto é, da formação do leitor e escriba em sua plenitude (NORRIS; PHILLIPS, 2003): com capacidade de compreensão, elaboração de significados, análise e crítica. Ao mesmo tempo, posiciona-se o ensino de ciências dentro de uma estrutura educacional (HOLBROOK; RANNIKMAE, 2007), no qual, somando-se a outras áreas de saber, formam-se pessoas com condições de pensar de forma autônoma. Nestes termos, a alfabetização científica é necessária para todos os indivíduos, imprescindível tanto para os que atuam ou vão atuar em atividades intelectuais quanto para os que atuam ou vão atuar em setor de serviços mecanizados com rotinas invariáveis. Por outro lado, esta perspectiva de alfabetização científica não encerra nem abarca todos os aspectos do processo de educação científica. Vivenciar o processo de alfabetização 
científica tal como ocorre em relação à alfabetização na língua materna não garante o seu uso dentro dos moldes aqui especificados.

\section{Considerações finais}

Neste trabalho, demarcamos os significados dos termos alfabetização e letramento, revisamos o histórico da expressão scientific literacy e delimitamos o contexto no qual esta expressão pode ser traduzida por alfabetização científica: quando esta se referir à escrita e à leitura de texto científico e a tudo aquilo que envolver estas duas habilidades, como a construção de entendimento e a análise das informações. Fundamenta-se, assim, a compreensão de que a alfabetização científica está atrelada à alfabetização na própria língua. Esta última alfabetização não estaria completa, não atingiria um grau maior de amplitude sem a primeira. Por conseguinte, o ensino de ciências seria concebido (com elaboração de propostas e condições de efetivação) no âmbito das necessidades educacionais do país, tendo por norte as contribuições que a alfabetização, em princípio, traria para a formação de indivíduos.

O ensino de ciências concebido à luz de objetivos educacionais mais amplos que o aprendizado de ciências per si (conhecimentos e procedimentos), assumido como parte da alfabetização, implica práticas pedagógicas que, a um só tempo, envolvem e desenvolvem: atividade intelectual, pensar crítico e autônomo, mobilização consciente e intencional de recursos cognitivos e metacognitivos. Para construirmos estas práticas, talvez mudanças de postura se façam necessárias e, certamente, uma nova agenda de pesquisa também. Por exemplo, precisaríamos entender mais: as relações de similaridade entre os processos de leitura e escrita e a elaboração e condução de atividades de investigação científica; como se ensina a identificar uma evidência como tal; como podemos ensinar a observar, descrever, interpretar, explicar, além de construirmos instrumentos para avaliar indicadores da alfabetização científica ${ }^{3}$. Não menos relevante seria ampliarmos a compreensão do que é letramento científico, que proximidades e que especificidades este apresenta em relação à alfabetização científica. Por fim, reconhecemos que muito do que aqui foi dito não é novidade no cenário do ensino das ciências nacional. Ainda assim, são princípios que precisam ser ditos, repetidos, reafirmados no momento presente, diante da crescente sinalização de propostas que priorizam a formação de professores para o ensino das ciências esvaziada de uma perspectiva educacional mais ampla, tal como pode ser verificado em algumas propostas de cursos de licenciatura e mestrado profissionalizante e, até mesmo, no Plano Nacional de Educação 2011-2020 (meta 7, estratégia 7.25) (BRASIL, 2011).

\footnotetext{
${ }^{3} \mathrm{O}$ trabalho de Sasseron e Carvalho (2008) é um excelente exemplo neste sentido. 
Alfabetização científica: questões para reflexão

\section{Referências}

AULER, D.; DELIZOICOV, D. Alfabetização científico-tecnológica para quê?

Ensaio - Pesquisa em Educação em Ciências, Belo Horizonte, v. 3, n. 1, jun. 2001.

Disponível em: <http://www.portal.fae.ufmg.br/seer/index.php/ensaio/article/viewFile/

44/203>. Acesso em: 06 nov. 2013.

BRASIL. Câmara dos Deputados. Projeto de lei do Plano Nacional de Educação (PNE 2011-2020). Brasilia: Edições Câmara, 2011. Disponível em: <http://www.unb.br/ administracao/decanatos/dex/formularios/Documentos\%20normativos/DEX/ projeto_de_lei_do_plano_nacional_de_educao_pne_2011_2020.pdf >. Acesso em: 25 nov. 2013.

BYBEE, R. W. The Sputnik era: why is this educational reform different from all other reforms? In: SYMPOSIUM REFLECTING ON SPUTINIK; LINKING THE PAST, PRESENT, AND FUTURE OF EDUCATIONAL REFORM, 1997, Washington.

Papers... Washington: National Academy of Sciences, 1997. Disponível em: <http:// www.nationalacademies.org/sputnik/bybee1.htm>. Acesso em: 06 nov. 2013.

CENTRAL do Brasil. Direção: Walter Salles Júnior. Produção: Martire de ClermontTonnerre e Arthur Cohn. Intérpretes: Fernanda Montenegro; Marilia Pera; Vinicius de Oliveira; Sônia Lira; Othon Bastos; Matheus Nachtergaele e outros. Roteiro: Marcos Bernstein, João Emanuel Carneiro e Walter Salles Júnior. [S.l.]: Le Studio Canal; Riofilme; MACT Productions, 1998. Disponível em: <http://www.youtube.com/ watch?v=kfOOjqr-yjQ>. Acesso em: 25 nov. 2013.

CHASSOT, A. Alfabetização científica: questões e desafios para a educação. Ijuí: Editora Unijuí, 2000.

DEBOER. G. E. Scientific literacy: another look at its historical and contemporary meanings and its relationship to science education reform. Journal of Research in Science Teaching, Hoboken, v. 37, n. 6, p. 582-601, 2000. Disponível em: <http:// web.nmsu.edu/ susanbro/eced440/docs/scientific_literacy_another_look.pdf $>$. Acesso em: 06 nov. 2013.

GREAT BRITAIN. House of Commons Public Accounts Committee. Skills for life: progress in improving adult literacy and numeracy: third report of session 2008-09. London, 2009. Disponível em: < http://www.publications.parliament.uk/pa/cm200809/ cmselect/cmpubacc/154/154.pdf>. Acesso em: 25 nov. 2013.

HOLBROOK, J.; RANNIKMAE, M. The meaning of scientific literacy. International Journal of Environmental \& Science Education, Bolu, v. 4, n. 3, p. 275-288, 2009. Disponível em: < http://www.ijese.com/IJESE_v4n3_Special_Issue_Holbrook.pdf > . Acesso em: 06 nov. 2013.

The nature of science education for enhancing scientific literacy. International Journal of Science Education, Abingdon, v. 29, n. 11, p. 1347-1362, 2007. Disponível em: <http://www.tandfonline.com/doi/abs/10.1080/09500690601007549\#preview>. Acesso em: 06 nov. 2013. 
Teixeira, F. M.

HURD, P. D. Scientific literacy: new minds for a changing world. Science Education, Hoboken, v. 82, n. 3, p. 407-416, 1998.

INSTITUTO BRASILEIRO DE GEOGRAFIA E ESTATÍSTICA. Pesquisa Nacional por Amostra de Domicílios 2009. Disponível em: <http://www.ibge.gov.br/home/ estatistica/populacao/trabalhoerendimento/pnad2009/>. Acesso em: 06 nov. 2013.

KATO, M. No mundo da escrita: uma perspectiva psicolinguística. São Paulo: Ática, 1986.

LAUGKSCH, R. C. Scientific literacy: a conceptual overview. Science Education, Hoboken, v. 84, n. 1, 71-94, 2000.

LIMA, P. H. F.; CASTRO, M. E. C. Educação em ciências, letramento e cidadania. Química Nova na Escola, São Paulo, n. 26, p. 3-9, nov. 2007. Disponível em: < http:// qnesc.sbq.org.br/online/qnesc26/v26a02.pdf>. Acesso em: 06 nov. 2013.

LIU, Z. A.; AKERSON, V. L. Science and language links: a fourth grade intern's attempts to use language arts to improve scientific inquiry skills. Electronic Journal of Literacy

Through Science, Davis, v. 1, n. 2, p. 1-19, 2002. Disponível em: <http://

ejlts.ucdavis.edu/sites/ejlts.ucdavis.edu/files/articles/zale.pdf>. Acesso em: 06 nov. 2013.

MAMEDE, M.; ZIMMERMANN, E. Letramento científico e CTS na formação de professores para o ensino de física. In: SIMPÓSIO NACIONAL DE ENSINO DE FÍSICA, 16., 2005, Rio de Janeiro. Anais... Disponível em: < http://

www.sbf1.sbfisica.org.br/eventos/snef/xvi/cd/resumos/T0264-1.pdf>. Acesso em: 06 nov. 2013 .

MARCUSCHI, L. A. Da fala para a escrita: atividades de retextualização. 7. ed. São Paulo: Cortez, 2007.

MARTINS, I. Alfabetização científica: metáfora e perspectiva para o ensino de ciências.

In: ENCONTRO DE PESQUISA EM ENSINO DE FÍSICA, 11., 2008, Curitiba. Anais... Disponível em: <http://www.sbf1.sbfisica.org.br/eventos/epef/xi/sys/resumos/

T0242-1.pdf>. Acesso em: 07 nov. 2013.

NORRIS, S. P.; PHILLIPS, L. M. How literacy in its fundamental sense is central to scientific literacy. Science Education, Hoboken, 87, n. 2, p. 224-240, mar., 2003.

Disponível em: <http://dx.doi.org/ 10.1002/sce.10066>. Acesso em: 07 nov. 2013.

PAULA, H. F.; LIMA, M. E. C. Educação em ciências, letramento e cidadania. Química

Nova na Escola, São Paulo, n. 26, p. 3-9, nov. 2007. Disponível em: <http://

qnesc.sbq.org.br/online/qnesc26/v26a02.pdf>. Acesso em: 07 nov. 2013.

PEGG, J. Integrating literacy into elementary science: teacher concerns and their resolutions.

Electronic Journal of Literacy Through Science, Davis, v. 9, p. 1-17, 2010. Disponível em: <http://ejlts.ucdavis.edu/sites/ejlts.ucdavis.edu/files/articles/Pegg_EJLTS_final.pdf >. Acesso em: 07 nov. 2013. 
Alfabetização científica: questões para reflexão

SANDER, B. Educação na América Latina: identidade e globalização. Educação, Porto Alegre, v. 31, n. 2, p. 157-165, maio/ago. 2008. Disponível em: <http:// revistaseletronicas.pucrs.br/ojs/index.php/faced/article/view/2766/2113>. Acesso em: 07 nov. 2013.

SANTOS, W. L. P. Educação científica na perspectiva de letramento como prática social: funções, princípios e desafios. Revista Brasileira de Educação, Rio de Janeiro, v. 12, n. 36, p. 474- 492, set./dez. 2007.

SANTOS, W.; MORTIMER, E. F. Tomada de decisão para ação social responsável no ensino de ciências. Ciência \& Educação, Bauru, v. 7, n. 1, p. 95-111, 2001. Disponível em: <http://dx.doi.org/10.1590/S1516-73132001000100007>. Acesso em: 07 nov. 2013.

SASSERON, L. H.; CARVALHO, A. M. P. Almejando a alfabetização científica no ensino fundamental: a proposição e a procura de indicadores do processo. Investigações em Ensino de Ciências, Porto Alegre, v. 13, n. 3, p. 333-352, 2008. Disponível em: <http:// www.if.ufrgs.br/ienci/artigos/Artigo_ID199/v13_n3_a2008.pdf>. Acesso em: 07 nov. 2013.

SOARES, M. Alfabetização: a ressignificação do conceito. Alfabetização e Cidadania, São Paulo, n. 16, p. 9-17, 2003.

Letramento: um tema em três gêneros. 2. ed. Belo Horizonte: Autêntica, 1998.

. Letramento e alfabetização: as muitas facetas. Revista Brasileira de Educação, Rio de Janeiro, n. 25, p. 5-17, 2004. Disponível em: < http://dx.doi.org/10.1590/

S1413-24782004000100002>. Acesso em: 07 nov. 2013.

Alfabetização e letramento. 5 ed. São Paulo: Contexto, 2008.

TFOUNI, L. V. Adultos não alfabetizados: o avesso do avesso. Campinas: Pontes, 1988.

UNESCO. Reaching the marginalized. Paris: Unesco; Oxford: Oxford University Press, 2010. Disponível em: <http://www.unesco.org/en/efareport/reports/2010marginalization/>. Acesso em: 25 nov. 2013.

U. S. DEPARTMENT OF EDUCATION. National Center for Education Statistics. National Assessment of Adult Literacy (NAAL). Demographics: overall. [S.l.: s. n., 2004]. Disponível em: <http://nces.ed.gov/naal/kf_demographics.asp\#3>. Acesso em: 25 nov. 2013.

YORE, L.; PIMM, D.; TUAN, H.-L. The literacy component of mathematical and scientific literacy. International Journal of Science and Mathematics Education, Dordrecht, v. 5, n. 4, p. 559-589, 2007. 